IZA DP No. 8287

The Effect of Conflict History on Cooperation Within and Between Groups: Evidence from a Laboratory Experiment

Gonne Beekman

Stephen L. Cheung

lan Levely

June 2014 


\title{
The Effect of Conflict History on Cooperation Within and Between Groups: Evidence from a Laboratory Experiment
}

\author{
Gonne Beekman \\ Wageningen University
}

\author{
Stephen L. Cheung \\ University of Sydney \\ and IZA
}

Ian Levely

Charles University in Prague

\author{
Discussion Paper No. 8287 \\ June 2014
}

IZA

\author{
P.O. Box 7240 \\ 53072 Bonn \\ Germany
}

\author{
Phone: +49-228-3894-0 \\ Fax: +49-228-3894-180 \\ E-mail: iza@iza.org
}

\begin{abstract}
Any opinions expressed here are those of the author(s) and not those of IZA. Research published in this series may include views on policy, but the institute itself takes no institutional policy positions. The IZA research network is committed to the IZA Guiding Principles of Research Integrity.

The Institute for the Study of Labor (IZA) in Bonn is a local and virtual international research center and a place of communication between science, politics and business. IZA is an independent nonprofit organization supported by Deutsche Post Foundation. The center is associated with the University of Bonn and offers a stimulating research environment through its international network, workshops and conferences, data service, project support, research visits and doctoral program. IZA engages in (i) original and internationally competitive research in all fields of labor economics, (ii) development of policy concepts, and (iii) dissemination of research results and concepts to the interested public.
\end{abstract}

IZA Discussion Papers often represent preliminary work and are circulated to encourage discussion. Citation of such a paper should account for its provisional character. A revised version may be available directly from the author. 


\section{ABSTRACT \\ The Effect of Conflict History on Cooperation Within and Between Groups: Evidence from a Laboratory Experiment ${ }^{\star}$}

We study cooperation within and between groups in the laboratory, comparing treatments in which two groups have previously been (i) in conflict with one another, (ii) in conflict with a different group, or (iii) not previously exposed to conflict. We model conflict using an intergroup Tullock contest, and measure its effects upon cooperation using a multi-level public good game. We demonstrate that conflict increases cooperation within groups, while decreasing cooperation between groups. Moreover, we find that cooperation between groups increases in response to an increase in the efficiency gains from cooperation only when the two groups have not previously interacted.

JEL Classification: C92, D64, D74, H41

Keywords: within- and between-group cooperation, inter-group conflict, group identity, multi-level public good experiment, Tullock contest, other-regarding preferences

Corresponding author:

Stephen L. Cheung

School of Economics

Merewether Building $\mathrm{H} 04$

The University of Sydney

NSW 2006

Australia

E-mail: Stephen.Cheung@sydney.edu.au

\footnotetext{
*We thank Klaus Abbink, Daniel Friedman, Simon Gächter, and Werner Güth; seminar audiences at the University of New South Wales, Monash University and University of Sydney; and participants in the Trento Summer School on Evolution of Social Preferences in July 2011, the Wageningen International Conference on Cooperation or Conflict in May 2013, the Workshop on Competition between Conflict and Cooperation in Freiburg in June 2013, the International Meetings of the Economic Science Association in Zurich in July 2013, the Australia and New Zealand Workshop on Experimental Economics in Brisbane in August 2013, the Asia-Pacific Meetings of the ESA in Auckland in February 2014, and the Thurgau Experimental Economics Meeting on Cooperation and Competition Within and Between Groups in May 2014.
} 


\section{Introduction}

In many interesting settings, a period of conflict or competition between groups is followed by the opportunity for mutually beneficial cooperation between the same groups. Examples include the formation of a coalition government following an election, the integration of work teams following a corporate merger, and the reunification of a nation after a period of civil conflict. In such situations, individuals are faced with a choice between acting in their own self-interest, in the parochial interests of their "in-group", or in the collective interests of all parties.

If, as a result of the prior history of conflict, individuals are reluctant to cooperate with members of an "out-group", the result may be substantial efficiency losses to society as a whole. Yet, at the same time, a shared experience of conflict may also reinforce cooperative norms among members of an in-group. To give an extreme example: two decades after the wars in the Balkans, Muslims and Christians in Bosnia have established separate schools and even separate fire departments (Brunwasser, 2011). This clearly illustrates these groups' preference to invest in "local" public goods that only benefit members of their in-group, as opposed to "global" public goods that benefit all parties.

There are several possible reasons why conflict may inhibit subsequent cooperation between groups. Firstly, the underlying reasons for the conflict could also have an effect on cooperation. Secondly, conflict could create or deepen in-group identity, strengthening other-regarding preferences toward in-group members and making it more attractive to cooperate within groups. Finally, conflict may create animosity towards out-group members, eroding other-regarding preferences towards out-group members and making it less attractive to cooperate between groups.

In this paper, we report a laboratory experiment designed to study how cooperative behavior, both within and between groups, is influenced by the group members' experience of a prior phase of conflict. In particular, we compare levels of within- and between-group cooperation in the situation described above - where the same two groups were previously in conflict - to a comparable situation in which each group previously experienced conflict involving a different out-group, as well as when group members have no prior experience of conflict. We vary this group matching on a between-subjects basis.

Since exposure to conflict is exogenous and randomly-assigned in our experiment, we can set aside the first explanation - namely that conflict and cooperation share some common and deeper source. Our group matching manipulations then enable us to disentangle the latter two mechanisms, to independently identify the effects of a shared experience of conflict upon other-regarding preferences toward members of the in- and out-groups. 
Our instrument for measuring cooperation within- and between-groups is a multi-level public good (MLPG) game (Blackwell and McKee, 2003). In this game, all individuals have an endowment which they can retain for private consumption, contribute to a local public good that benefits only members of the in-group, and/or a global public good that benefits members of both the in- and out-groups. Our conflict manipulation takes the form of an inter-group version of the Tullock rent-seeking contest (Tullock, 1980; Abbink et al., 2010). The Tullock game thus models a prior phase of inter-group conflict which is followed by a subsequent opportunity for cooperation in the form of the MLPG game.

Previous studies of the MLPG game typically find that contributions to the global public good are increasing in the relative return on the global account compared to the local one (Blackwell and McKee, 2003; Fellner and Lünser, 2008; Chakravarty and Fonseca, 2013). However, since the Tullock contest potentially induces a much stronger form of in- and out-group identity than has previously been considered in this literature, this responsiveness to efficiency considerations may not be robust to a shared history of conflict involving the same out-group. For this reason, we vary the return on contributions to the global public good as a second dimension of our experiment design.

Our approach thus introduces a number of methodological innovations. Firstly, we go beyond standard arbitrary or minimal methods of group formation, by using inter-group competition in a Tullock contest to instil a much stronger form of induced group identity - forged in conflict against another group - in the laboratory. Secondly, through our manipulations of group matching across the two phases of our experiment, we are able to disentangle the in- and out-group effects of this conflict manipulation upon subsequent interactions in the MLPG game.

Our results are directionally consistent with a simple model of other-regarding preferences in which conflict increases the utility weight on payoffs for members of the in-group, while decreasing the weight on payoffs of the out-group. We find that within-group cooperation increases when groups have a shared history of conflict compared to when they play the MLPG without any prior history, while between-group cooperation diminishes when two groups have previously been in conflict. We find no significant response to an increase in the return to between-group cooperation when there has been a prior history of conflict between the groups - which is contrary to the results of previous studies that induce weaker forms of group identity. On the other hand, when two groups have not previously interacted (but each has nonetheless previously experienced conflict involving a different out-group) we find a significant increase in between-group cooperation in response to an increase in its return - which is in line with the results of the previous literature.

The paper proceeds by reviewing the relevant literature in Section 2, before Section 3 sets out our experimental design. Section 4 develops a simple model of other-regarding 
preferences in the MLPG game, from which we derive hypotheses regarding the effects of our treatments. Section 5 presents and discusses our results, and Section 6 concludes.

\section{Related literature}

Our paper contributes to two strands of literature. First, we make a methodological contribution to the literature on inducing group identity in laboratory experiments. The most widely used method of doing so, the "minimal group paradigm" introduced by Tajfel (1971) in the social psychology literature, involves forming groups on the basis of seemingly irrelevant personal characteristics - such as preference for a particular abstract painting by either Klee or Kandinsky - and has been found to be sufficient to induce a bias in favor of members of the in-group in many psychological experiments (Tajfel and Turner, 1979). This method has also been widely applied in economic experiments, although usually in a modified form. ${ }^{1}$ In these studies, assigning group membership randomly according to number or color, or according to trivial preferences, has not always been sufficient to induce an in-group bias. However, using these procedures in a modified form, and/or in combination with other methods designed to increase the salience of group membership, has been found to be effective.

One notable example is Chen and Li (2009), who use the Klee/Kandinsky procedure and find that subjects are more likely to choose social-welfare maximizing actions in allocation games when playing with in-group members. In their setting, shared identity deriving from a trivial preference for one painter over another is only effective in producing differences in behavior toward in- and out-group members when combined with anonymous communication with the in-group members during a problem-solving task. Similarly, Charness et al. (2007) find that in-group preferences are stronger when an individual's choices are observed (passively) by in-group members, whereas arbitrarily labeling groups and identifying them with colors or numbers is not enough to create an in-group bias in Prisoner's Dilemma and battle-of-the-sexes games.

Eckel and Grossman (2005) compare the effects of several methods for creating group identity in a laboratory experiment, comparing cooperation in a public good game played under various degrees of induced group identity, including arbitrary group identity (in which groups are formed randomly then labeled by color only), as well as treatments in which identity is strengthened through joint participation in problem-solving tasks, and competition in a tournament (in which the group with the highest contribution to the

\footnotetext{
${ }^{1}$ As Chen and Li (2009) point out, the classic definition of the minimal group paradigm requires that any decisions made by a subject should not directly affect her own payoff. However this condition is violated in most economic experiments that use similar methods to induce group identity in the lab.
} 
public good receives a bonus which is deducted from the losing team's payoffs). They find that in-group cooperation is not affected by the arbitrary or problem-solving treatments, but is significantly higher when teams have participated in the tournament.

Our approach is similar to Eckel and Grossman (2005) in that we use competition as a means of making group identity more salient. However, our design differs in two key respects. First, we are able to examine and compare the effect of this group identity not only on in-group cooperation after competition, but also on cooperation with an outgroup. Second, we strengthen group identity through competition that produces a social loss, which may cause a different change in preferences than productive competition.

Our design uses a Tullock contest (Tullock, 1980) - in which two parties choose how much to invest in a (wasteful) competition over a fixed resource - to increase the salience of group membership. This is the first study we are aware of to employ the Tullock game as a means of inducing group identity in order to study subsequent interactions.

In the Tullock game, although any expenditure on competition is inherently socially inefficient, the equilibrium level of investment is positive. In previous experiments, contest investments have far exceeded equilibrium predictions (see Sheremeta (2013) for a survey). Moreover, playing the Tullock game in a group environment seems to matter: Abbink et al. (2010) find that investments in a Tullock contest are even further above the equilibrium prediction when the game is played in teams rather than individually. One possible explanation for this finding is that group membership increases utility gains from winning the contest, which is consistent with the interpretation that group identity and competition are intertwined.

Abbink (2012) advocates greater experimental research on the Tullock contest as a "natural workhorse" for the study of conflict. In one such study, Ke et al. (2013) find that when a pair competes together as a team against a third individual, any in-group solidarity formed during this first stage does not diminish the intensity of subsequent conflict when the team members compete over the spoils in a second Tullock contest.

Halevy et al. (2012) also examine how changes in incentives for intra-group competition affect subsequent interactions. Individuals can choose to cooperate with their in-group while simultaneously harming the out-group, and after a set number of rounds some individuals are given the option to cooperate with their in-group without harming the out-group. The authors find that individuals prefer to cooperate with in-group members without imposing negative externalities on the out-group, and this is true even after a phase of conflict in which in-group cooperation is necessarily associated with negative externalities, resulting in high rates of harm to the out-group. 
Our study is similar to these experiments in that we are concerned with how conflict between groups affects subsequent interactions. However, we study an environment in which incentives favor conflict in the first phase, and then observe how this affects cooperation between groups (as opposed to further competition) in a second phase.

This brings us to the second body of literature to which our paper contributes, on cooperation within and between groups - including both groups formed endogenously in the naturally-occurring world as well as ones formed in the lab. Findings from a number of economic experiments show that group membership leads to more within-group cooperation (Puurtinen and Mappes, 2009), but decreases between-group cooperation. Therefore, stronger group identity may lead to efficiency gains due to increased withingroup cooperation, but efficiency losses associated with reduced out-group cooperation.

Several papers use MLPG experiments to study inter-group interactions, generally finding that although subjects contribute non-zero amounts to the local public good, contributions to the global public good are higher, and responsive to its relative efficiency. Blackwell and McKee (2003) use arbitrary group identity - groups are formed randomly and identified by color - and find weak evidence for in-group preferences, but only when the average per-capita return to the global public good is no lower than that of the local public good. Fellner and Lünser (2008) study a similar experiment, identifying groups by letters and adding a monitoring mechanism to increase the salience of group identity. They find that contributions to the global public good are high when it is socially more efficient than the local public good, but that as cooperation decays over time, subjects switch toward the local public good.

Chakravarty and Fonseca (2013) assign subjects into groups using the Klee/Kandinsky procedure, and strengthen group identity using intra-group communication (through a chat-box on the computer screen, as in Chen and Li (2009)) before an MLPG game in which the efficiency of the local public good is varied across treatments. They find that even when the financial return to investing in the global public good is higher, subjects invest a considerable part of their endowment in the local ("club") good, hence reducing social efficiency. One possible reason for the somewhat stronger results of this study may be that it induces a more salient form of group identity than the two previous studies.

In addition to laboratory experiments, there are also a number of artefactual field experiments which measure the effects of naturally-occurring group identity on within- and between-group cooperation.

In a cross-cultural experiment, Buchan et al. (2009) use an adaption of the MLPG game - in which contributions to the local and global public goods do not directly affect current players, but instead accrue to individuals playing in a subsequent session - and 
find that increased exposure to globalization at both the individual and national level increases contributions to a global account that also accrues to citizens of other countries. The MLPG design allows them to separate preferences for cooperating with foreigners specifically from general variation in preferences for cooperation between countries.

The field experiment most closely related to our paper is Gumen (2012), who studies a variation of the MLPG game using students from fraternities at a US university. ${ }^{2}$ Groups of subjects from the same fraternity are matched with an out-group either from the same fraternity or from a rival fraternity, according to treatment. She finds that when subjects play with an out-group from the same fraternity, they over-invest in the global public good. However, when playing with an out-group from a rival fraternity, they invest comparatively more in the local public good.

In addition to material incentives, inter-group interactions may be motivated by preferences for cooperation within groups and competition between groups (Hirshleifer, 1995), which may have developed through evolutionary conditions that involved frequent conflict between small groups (Bowles and Gintis, 2011). Choi and Bowles (2007) hypothesize that war is instrumental in maintaining and strengthening "parochial altruism" (increased altruism towards in-group members coupled with hostility towards out-group members). In line with this theoretical prediction, recent empirical evidence on the effects of war on social preferences shows that war leads to more altruism towards neighbors (Voors et al., 2012), stronger egalitarian norms towards in-group members by children (Bauer et al., 2014), and more within-group cooperation (Gneezy and Fessler, 2012).

Our study is related to this literature, but focuses on the role that simple conflict in the form competition over a fixed resource - as distinct from exposure to violence or other trauma - plays in shaping social preferences. We contribute to the discussion of group identity and cooperation by disentangling how conflict affects other-regarding preferences toward the in- and out-groups, using competition in the Tullock contest as novel means of inducing group identity in the laboratory.

\section{Design}

Our experiment consists of two stages: a group Tullock contest and an MLPG game, both of which are played between two groups of three subjects in each of our treatments. Groups are formed randomly and anonymously at the beginning of the session, and the membership of a subject's "in-group" remains the same throughout the experiment. In each stage, each group is paired with a second group (the "out-group") for ten rounds of

\footnotetext{
${ }^{2}$ In Gumen's design, the payoff function is non-linear, with an interior optimum for a selfish agent.
} 
repeated play, with one round of each game randomly selected to count for payment at the end of the experiment. The identity of the out-group remains constant across all ten rounds of a given game. However, it may change between games according to treatment.

We use the Tullock contest primarily to manipulate subjects' experience of conflict - both as a member of their in-group, and in opposition to an out-group. We use the MLPG game to measure the effect of these conflict manipulations upon subjects' willingness to cooperate both within their in-group as well as between the in- and out-groups. In particular, in our arbitrary-groups treatment, subjects play the MLPG game as the first stage of the experiment, without any prior experience of the Tullock contest. In this treatment, subjects play the MLPG game without any previous history of interaction with the members of their in- or out-groups. This treatment thus constitutes a baseline measure of cooperativeness in the absence of any interaction history.

In our rematched-groups treatments, subjects play the Tullock contest as the first stage. However, they are rematched with a new out-group before playing the MLPG game. In these treatments, subjects have previously interacted with the other members of their in-group, but not the out-group, prior to playing the MLPG game. This enables us to identify the effect of the experience of conflict in potentially strengthening other-regarding preferences toward members of the in-group. Finally in our fixed-groups treatments, subjects play the Tullock contest first, and are then paired with the same out-group for the MLPG game. As a result, they have previously interacted with both their in- and out-groups prior to playing the MLPG game. This enables us to identify the effect of the experience of conflict in weakening other-regarding preferences toward the out-group.

In addition, in our fixed- and rematched-groups treatments, we also vary the return on cooperation between groups in the MLPG game, in the form of the marginal per-capita return (MPCR) on contributions to the global account that benefits the members of both the in- and out-groups. We do this to study how our conflict manipulations influence the extent to which subjects respond to efficiency considerations.

\subsection{Tullock contest}

The Tullock contest (Tullock, 1980) models an unproductive conflict between two parties over an exogenous prize $P$. In our implementation of this game, we take each group to be a party to the contest, with the prize to be contested between two groups and then divided equally among the three members of the winning group. In each round, each group has an endowment $y$, and must choose an amount $x$ to invest in its "contest fund" to increase its chances of winning the prize. Given the investments of the two groups, $x_{g}$ and $x_{h}$, the probability that group $g$ is the winner is given by: 


$$
\operatorname{Pr}\left(P \mid x_{g}, x_{h}\right)=\frac{x_{g}}{x_{g}+x_{h}}
$$

and the expected payoff to group $g$ in a given round of the game is:

$$
\Pi_{g}=\left(y-x_{g}\right)+\frac{x_{g}}{x_{g}+x_{h}} P
$$

The Tullock game has a unique equilibrium (in terms of total group investments) which can be found by taking the first-order condition of $\Pi_{g}$ with respect to $x_{g}$ and setting $x_{g}=x_{h}=x^{*}$ such that each group invests $x^{*}=P / 4$ in its respective contest fund.

We give each group an aggregate endowment of $y=300$, and the two groups compete over a prize of the same value (i.e. $P=300$ ), implying an equilibrium investment of $x^{*}=75$ for each group. Since the prize is split equally among members of the winning group, each group member receives $P / 3=100$ in the event that their group is the winner.

To conduct the Tullock game in groups while preserving the unique equilibrium, and also to avoid wealth effects among the members of an in-group (which might influence their contribution decisions in a subsequent MLPG game), we determine investments in the group contest fund using a median-voter rule. Each group member is given an endowment of $y_{i}=y / 3=100$, and is obliged to invest the median of the amounts proposed by the three members of their in-group, with no possibility to free-ride. In equilibrium, each individual's share of the group investment is thus $x^{*} / 3=25$.

Under the median-voter rule, no individual has any incentive to deviate from proposing their own true preferred level of investment, even where this differs from the risk-neutral Nash investment, for example as a result of social or risk preferences. In each round, before the draw to determine the winning group occurs, subjects receive feedback on the median investment proposed by the members of their own group, the resulting allocation of their group to the contest fund, the allocation of the rival group, and their group's resultant probability of being the winner. After this, the draw to determine the winner takes place and subjects are informed of the result before continuing to the next round.

\subsection{Multi-level public good game}

In the MLPG game, each subject is given an individual endowment of $\omega_{i}=100$ in each round. Each subject must decide how to allocate this endowment between three accounts: a private account that benefits the individual alone, a local public good that benefits the three members of the in-group only, and a global public good that benefits six individuals: the three members of the in-group as well as the three members of the out-group with whom they have been matched. In the instructions, these three alternatives are framed neutrally as accounts $\mathrm{A}, \mathrm{B}$ and $\mathrm{C}$. 
Given the contribution decisions of all six players, the monetary payoff to individual $i$ in any given round of the game is:

$$
\pi_{i}=\left(\omega_{i}-c_{i}-C_{i}\right)+\frac{\alpha}{n} \sum_{j=1}^{n} c_{j}+\frac{\beta}{2 n} \sum_{k=1}^{2 n} C_{k}
$$

where $c_{i}$ denotes a contribution to the local public good that benefits the $n=3$ members of the in-group and $C_{i}$ denotes a contribution to the global public good that benefits the $2 n=6$ members of both the in- and out-groups.

Allocations to the private account always yield a return of 1 , accruing to the individual alone. In all treatments, the sum of contributions to the local public good, by all three members of the in-group, is multiplied by a factor of $\alpha=1.5$ and divided equally between them, giving an MPCR from the local account of $\alpha / n=0.5$.

Similarly, the sum of contributions to the global public good, by all six members of the inand out-groups, is multiplied by a factor of $\beta$ and divided equally between them. We vary the return to the global account between treatments. In our low-gains-from-cooperation treatments we set $\beta=2$, giving an $M P C R$ on the global account of $\beta / 2 n=0.33$, while in our high-gains treatments we set $\beta=3$, giving an $M P C R$ of $\beta / 2 n=0.5$.

Since $\beta / 2 n \leq \alpha / n<1$ in all treatments, an individual who cares only about her own material payoff will contribute nothing to either of the public goods, just as in a standard (single-level) public good game. On the other hand, since $\beta>\alpha>1$ in all treatments, full contribution to the global account is always the most socially efficient outcome.

\subsection{Treatments}

By manipulating the nature of the prior group interactions (if any) before the play of the MLPG game, we are able to identify the effect that exposure to inter-group conflict, involving either the same or a different out-group, has upon preferences for both intraand inter-group cooperation, and thus examine how subjects' other-regarding preferences are shaped by the experience of conflict. Moreover, by manipulating the gains from cooperating with the out-group as well, we are also able to measure the response to efficiency considerations, and in particular whether this differs between treatments in which subjects are exposed to the same, or to a different, out-group in the MLPG game.

In total, we have five treatments in a $(2 \times 2)+1$ design. Firstly, we interact the dimension of fixed-versus rematched-groups with that of low versus high gains from cooperation. This results in four treatments: fixed groups with low / high gains from cooperation (FL and $\mathrm{FH}$, respectively) and rematched groups with low / high gains from cooperation (RL 
and $\mathrm{RH}$, respectively). In these four treatments, the Tullock contest is played as the first stage to induce a prior experience of conflict before playing the MLPG game.

In addition, we also include an arbitrary groups with low gains from cooperation treatment (AL), in which subjects play the MLPG game first (with low gains from cooperation) without any prior interaction with either their in- or out-groups, and then play the Tullock contest second (in a fixed group matching). This AL treatment captures baseline levels of cooperation with no prior experience of conflict as a group.

\subsection{Procedures}

The experiment was conducted at the Laboratory of Experimental Economics in Prague, Czech Republic between April 2012 and October 2013. We collected data for ten group pairs (with six subjects each) of the MLPG game in each of the five treatments. Subjects were recruited using ORSEE (Greiner, 2004) from a pool of students who had registered to participate in economic experiments. A total of 300 subjects took part in the experiment. Of these, $57 \%$ were undergraduates and $69 \%$ were males.

The experiment was conducted entirely in English. ${ }^{3}$ Sessions were conducted with 12-30 subjects at one time, and lasted around 75 minutes. All subjects in any given session were assigned to the same treatment. Two experimenters were present for each session, with the instructions read aloud by the same experimenter in all but one of the sessions. The experiment software was programmed using z-Tree (Fischbacher, 2007).

Upon entering the lab, subjects were randomly assigned to a computer terminal, and instructions were both read aloud and provided in print. ${ }^{4}$ At the beginning of the session, subjects were informed that they would complete two tasks, but they were not told anything about the second task until after they had completed the first one. Subjects were told that they would be matched into groups, and that these groups would remain anonymous both during and after the experiment.

In all treatments except for AL, the Tullock contest was played first, followed by the MLPG game. The instructions for the first game were read, and then subjects answered a series of control questions to ensure that they understood the task. After completing the first game, subjects were told that they would continue to the second task, and a

\footnotetext{
${ }^{3}$ The invitations to participate indicated clearly that the experiment would be conducted in English. All subjects completed a series of control questions (also in English) which serves to confirm that they were proficient enough in English to understand the instructions.

${ }^{4}$ The instructions for treatment RL are available online as Appendix B.
} 
similar procedure was followed again. The instructions clearly stated whether the outgroup matching was the same or different from the first task (according to the treatment), and that the composition of the in-group would remain unchanged across both tasks.

Each subject was paid for one round of the Tullock contest and one round of the MLPG game, chosen at random after both games had been completed. All payments were made in private; the average payment per subject was $250 \mathrm{CZK}$, which was equivalent to approximately $\$ 13$ USD at the time of the experiment.

\section{Theory}

\subsection{Model}

We now develop our hypotheses regarding the effects of our treatments upon the level of contributions to the local and global public goods in the MLPG game. We motivate these hypotheses with a very simple reduced-form model of other-regarding preferences. In particular we allow for the possibility that an agent may, in addition to their own material payoffs, attach some weight to the payoffs of others in the utility function. At the same time, we allow for the possibility that the agent may distinguish between members of the in- and out-groups in the weights that they assign to the payoffs of others.

Thus, let $a$ denote the value that an agent attaches to an extra unit of payoff to another member of the in-group, relative to a unit of own payoff, and let $b$ denote the weight attached to an extra unit of payoff to a member of the out-group. In reality, $a$ and $b$ are latent taste parameters that are heterogeneous across the population. However, for concreteness we speak of the effects of our treatments upon the tastes of a representative agent. We assume at minimum that $a, b \in(-1,1)$, with $a \geq b$. Then, taking into account the effect of contributions to the local and global public goods upon the payoffs of others, we augment the material payoff function (3) to write the utility function as: ${ }^{5}$

$$
U_{i}=\left(\omega_{i}-c_{i}-C_{i}\right)+\frac{\alpha}{n}[1+(n-1) a] \sum_{j=1}^{n} c_{j}+\frac{\beta}{2 n}[1+(n-1) a+n b] \sum_{k=1}^{2 n} C_{k}
$$

In our experiment design, $\alpha=1.5$ and $n=3$ are fixed, $\beta$ is varied as a treatment variable in our low and high gains from cooperation conditions, and we hypothesize that our arbitrary, rematched and fixed group assignment conditions will shift the other-regarding preference parameters $a$ and $b$ in a manner that we describe below.

\footnotetext{
${ }^{5}$ Clearly, equation (4) omits payoffs that others derive from allocations to their own private accounts. We do this to focus on the indirect, but partial, effects of an agent's own contributions to the local and global public goods upon their own utility. That is, we do not claim to provide a full equilibrium model.
} 

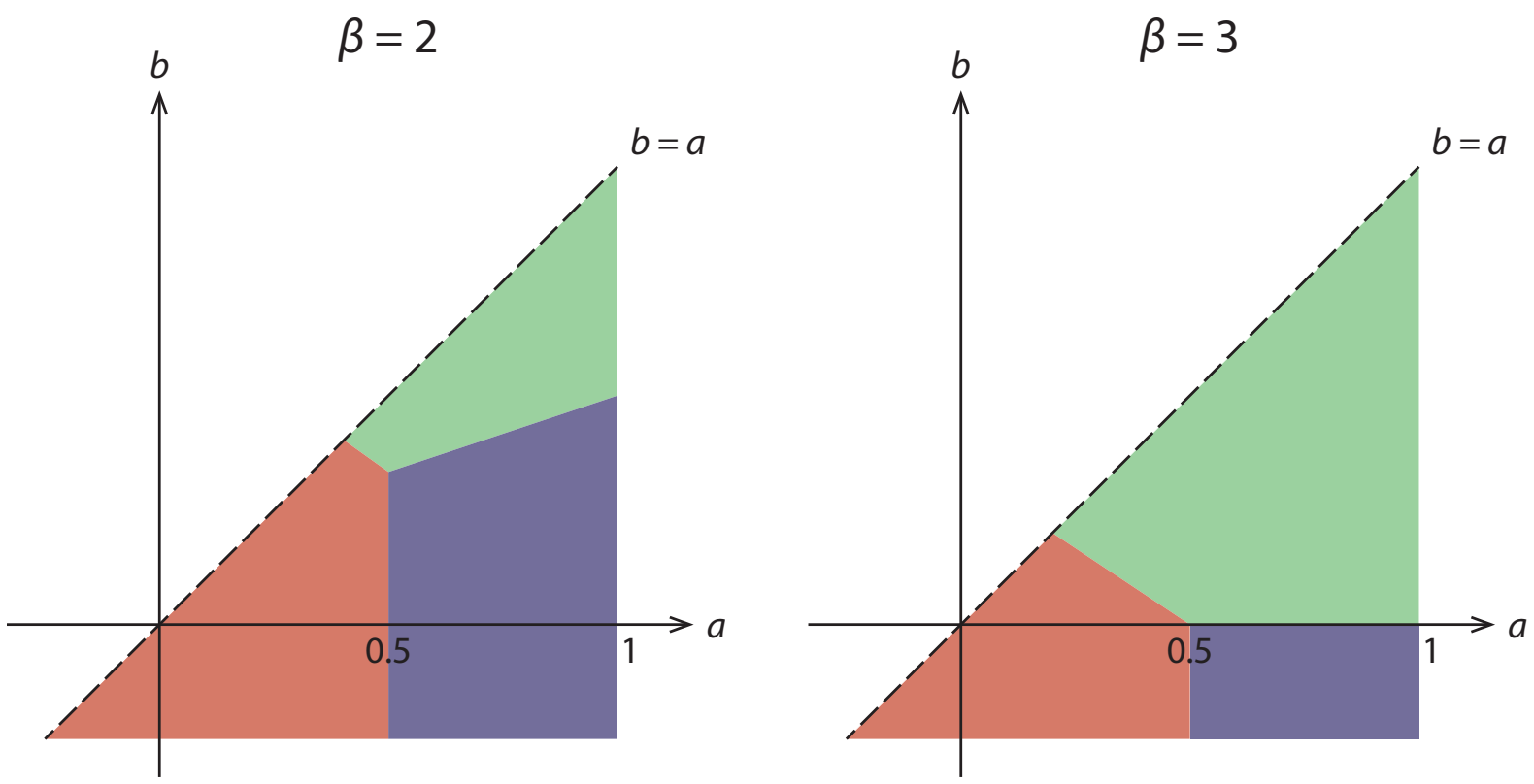

Given the linear specification of the payoff and utility functions, this model generates the highly stylized point prediction that an agent should always contribute fully to whichever account yields the highest marginal benefit - respectively $1,0.5(1+2 a)$, and $\frac{\beta}{6}(1+2 a+3 b)$ for the private, local and global accounts. Figure 1 depicts the parameter configurations of $a$ and $b$ for which it is optimal to contribute to the private (red, lower left), local (blue, lower right) and global (green, upper right) accounts respectively. We depict these for the case of $\beta=2$ in the left-hand panel, and for $\beta=3$ on the right. While our model clearly oversimplifies in predicting only boundary allocations, it serves to generate some useful intuition which we illustrate with reference to some special cases.

Firstly, for the case of a purely selfish agent with $a=b=0$, the model yields the standard prediction that own material payoffs are maximized by allocating the entire endowment to the private account and contributing nothing to either the local or global public goods.

Secondly, consider the case $a>b=0$ in which an agent assigns positive weight to the payoffs of other members of the in-group, but is indifferent to the payoffs of the out-group. This corresponds to points along the horizontal axis in Figure 1. In this case, the agent will contribute to a public good if they are sufficiently regarding of the other members of the in-group, i.e. if $a>0.5$. Then, for $\beta=2$ it is optimal to contribute fully to the local account, while for $\beta=3$ the agent is indifferent between the local and global accounts.

Thirdly, consider the case $a=b>0$ in which the agent assigns equal and positive weight to the payoffs of all members of the in- and out-groups alike (i.e. the agent does not perceive any meaningful distinction between the two groups). This corresponds to points along the diagonal in Figure 1. In this case, the agent would contribute fully to the global 
Figure 2: Hypothesized effects of treatments upon model parameters

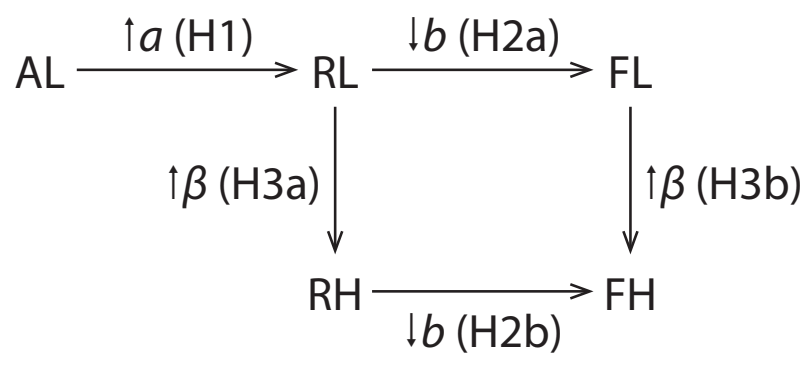

public good if $a=b>0.4$ for $\beta=2$, or $a=b>0.2$ for $\beta=3$. Otherwise, it is optimal to retain the entire endowment in the private account. It follows that, for both values of $\beta$ in our design, it is only optimal to contribute to the local account if the agent attaches less weight to the payoffs of members of the out-group than to the in-group, i.e. if $b<a$.

\subsection{Hypotheses}

Recall that our experiment design has two dimensions. Firstly, we manipulate the values of the other-regarding preference parameters $a$ and $b$ indirectly through our arbitrary, rematched and fixed group assignment conditions. Secondly, we vary the return on the global account $\beta$ directly in our low and high gains from cooperation conditions. In Figure 2 , we summarize the hypothesized effects of our treatments upon these three parameters.

Our first set of hypotheses are concerned with the effects of our group matching manipulations, operating through the other-regarding preference parameters $a$ and $b$.

In our arbitrary groups treatment, subjects had no prior interaction with either their inor out-groups before playing the MLPG game. By contrast, in our rematched groups treatments, they had previously interacted with their in-group in the Tullock contest - but with a different out-group. Finally, in our fixed groups treatments subjects had previously interacted with both the same in- and out-groups in the Tullock game.

We hypothesize firstly that, relative to the arbitrary groups condition, a shared experience of conflict may strengthen subjects' other-regarding preferences toward members of the in-group, as captured by the parameter $a$. This corresponds to a rightward movement in Figure 1, and has the effect of making contribution to the local account more attractive under both rematched and fixed groups.

We hypothesize secondly that, relative to rematched groups, a past experience of conflict with the same out-group may weaken subjects' other-regarding preferences toward members of the out-group, as captured by the parameter $b$. This corresponds to a downward 
movement in Figure 1, and has the effect of making contribution to the global account less attractive specifically under fixed groups only.

On the basis of these hypothesized effects, our model implies the following predictions:

Hypothesis 1: Contributions to the local account will be higher under the RL and FL treatments compared to the AL treatment.

Hypothesis 2a: Contributions to the global account will be lower under the FL treatment compared to the RL treatment.

Hypothesis 2b: Contributions to the global account will be lower under the FH treatment compared to the RH treatment.

Our next set of hypotheses are concerned with the second dimension of our experiment design in which we vary the gains from between-group cooperation as captured by the parameter $\beta$. It follows directly from equation (4) that an increase in $\beta$ will increase the marginal benefit to contributing to the global account. However, the magnitude of this increase depends also on the value of $b$, which we have hypothesized above to be attenuated under our fixed groups treatments. Accordingly, our model implies that:

Hypothesis 3a: Contributions to the global account will be higher under treatment RH compared to treatment RL.

Hypothesis 3b: Contributions to the global account will be higher under treatment FH compared to treatment FL. However, the magnitude of this increase will be smaller than under rematched groups.

\section{Results}

In Table 1, we report summary statistics of contributions in the MLPG game. ${ }^{6}$ For each treatment, we compute the mean allocation to each account pooled over all ten rounds, as well as mean earnings. ${ }^{7}$ The figures in parentheses are treatment standard deviations, treating group pairs as observations, i.e. we treat the mean in each group pair as a single observation and report the standard deviation for the ten group pairs in each treatment. ${ }^{8}$

\footnotetext{
${ }^{6}$ We report our analysis of the Tullock contest in Section 5.3 and Appendix Figure A1.

${ }^{7}$ Appendix Figure A2 depicts the time paths of mean individual allocations to the private, local and global accounts for each of the five treatments. It is clear that the ranking of the treatments with respect
} 
Table 1: Summary statistics (by group pairs)

\begin{tabular}{lccccl}
\hline Treatment & Obs & Private & Local & Global & Earnings \\
\hline Arbitrary Low & 10 & 59.2 & 7.7 & 33.2 & 137.0 \\
& & $(13.8)$ & $(4.1)$ & $(15.3)$ & $(14.4)$ \\
Rematched Low & \multirow{2}{*}{10} & 48.3 & 10.1 & 41.6 & 146.6 \\
& & $(23.5)$ & $(9.9)$ & $(22.3)$ & $(22.4)$ \\
Fixed Low & \multirow{2}{*}{10} & 46.4 & 15.0 & 38.6 & 146.1 \\
& & $(18.1)$ & $(9.3)$ & $(19.1)$ & $(18.0)$ \\
Rematched High & \multirow{2}{*}{10} & 36.1 & 5.4 & 58.5 & 219.6 \\
& & $(15.2)$ & $(4.4)$ & $(16.3)$ & $(31.9)$ \\
Fixed High & \multirow{2}{*}{10} & 48.0 & 7.5 & 44.5 & 192.7 \\
& & $(15.0)$ & $(4.0)$ & $(14.6)$ & $(29.1)$ \\
\hline
\end{tabular}

Note: standard deviations in parentheses.

Table 2: Wilcoxon rank-sum $p$-values (two-sided, by group pairs)

\begin{tabular}{llll}
\hline & Private & \multicolumn{1}{c}{ Local } & Global \\
\hline H1: RL vs. AL & 0.406 & 0.940 & 0.326 \\
H1: FL vs. AL & $0.049^{* *}$ & $0.041^{* *}$ & 0.496 \\
H2a: FL vs. RL & 0.821 & 0.290 & 0.821 \\
H2b: FH vs. RH & 0.112 & 0.290 & $0.059^{*}$ \\
H3a: RH vs. RL & 0.227 & 0.290 & $0.041^{* *}$ \\
H3b: FH vs. FL & 0.762 & $0.028^{* *}$ & 0.406 \\
\hline \multicolumn{4}{r}{ Note: ${ }^{*} p<0.10 ;{ }^{* *} p<0.05}$.
\end{tabular}

Table 1 indicates that contributions to the global account are highest, while allocations to the private account are lowest, under treatment $\mathrm{RH}$. On the other hand, contributions to the global account are lowest, while allocations to the private account are highest, under treatment AL. Contributions to the local account are low across all five treatments, with the highest level (at 15\%) observed under treatment FL. The ranking of the treatments with respect to earnings is identical to the ranking with respect to global contributions, even though the treatments differ with respect to the efficiency of the global public good, and there is also the opportunity to contribute to the less efficient local account.

In Table 2, we report two-sided $p$-values for Wilcoxon rank-sum tests of the equality of contributions, to each of the three accounts, in each pairwise comparison between treatments highlighted by our hypotheses. Again, this analysis treats the mean contribution of each group pair - by all six subjects and in all ten rounds - as a single observation.

to the level of contributions to each of the accounts is fairly stable over the ten rounds of the MLPG game, and there are no obvious differences in either the nature or slope of the time trends across treatments. For these reasons, we aggregate the data from all ten rounds throughout our analysis.

${ }^{8}$ We acknowledge that in treatments with rematched groups, the group pairs are not strictly speaking independent observations. This is because subjects have previously interacted with members of a different out-group in the first-stage Tullock contest, and this could potentially result in inter-dependencies in behavior across two group pairs. 
Table 3: Tobit regressions of mean individual contributions

\begin{tabular}{lccc}
\hline & Private & Local & Global \\
\hline H1: RL & -11.676 & 2.940 & 8.575 \\
& $(8.972)$ & $(4.278)$ & $(8.739)$ \\
H1: FL & $-13.003^{*}$ & $9.662^{* *}$ & 5.622 \\
& $(7.376)$ & $(3.899)$ & $(7.850)$ \\
RH & $-23.805^{* * *}$ & -4.825 & $26.238^{* * *}$ \\
& $(6.878)$ & $(3.100)$ & $(7.298)$ \\
FH & $-11.362^{*}$ & -1.844 & $11.550^{*}$ \\
& $(6.750)$ & $(2.630)$ & $(6.823)$ \\
\hline Observations & 300 & 300 & 300 \\
\hline H2a: FL vs. RL & 0.889 & 0.209 & 0.753 \\
H2b: FH vs. RH & $0.076^{*}$ & 0.388 & $0.039^{* *}$ \\
H3a: RH vs. RL & 0.186 & 0.113 & $0.048^{* *}$ \\
H3b: FH vs. FL & 0.826 & $0.007^{* * *}$ & 0.437
\end{tabular}

Notes: base category AL; robust standard errors clustered by group pairs. ${ }^{*} p<0.10 ;{ }^{* *} p<0.05 ;{ }^{* * *} p<0.01$.

Finally, in Table 3 we report an individual-level regression analysis of the effects of our treatments upon individual contributions to each of the three accounts. For each of the 300 subjects, we compute the mean amount allocated by that subject to each account over the ten rounds of the MLPG game. We regress these mean contributions on a set of dummies for each of the treatments, in a two-limit Tobit model with treatment AL as the omitted category. Each subject contributes one observation to each of the three regressions, and we report robust standard errors clustered at the level of group pairs. Table 3 also reports two-sided $p$-values for tests of the equality of the coefficients for each of the pairwise comparisons between treatments highlighted by our hypotheses.

On the basis of these analyses, we report our main results in the following two subsections.

\subsection{Effects of group matching}

Our first two hypotheses are concerned with the effects of our arbitrary, fixed and rematched groups manipulations, and correspond to the horizontal dimension in Figure 2. We summarize the effects of this dimension of our experiment design graphically in Figure 3, separately for each of the three accounts, and for treatments with low and high gains from cooperation. The confidence bars in this figure represent \pm 1 standard error of the mean, treating group pairs as observations.

Hypothesis 1 states that subjects' other-regarding preferences toward the members of their in-group may be strengthened when they have had the shared experience of playing the Tullock contest together. As a result, we expect contributions to the local public good to be higher under treatments RL and FL compared to treatment AL. 
A. Effect of Group Matching with Low Gains to Cooperation
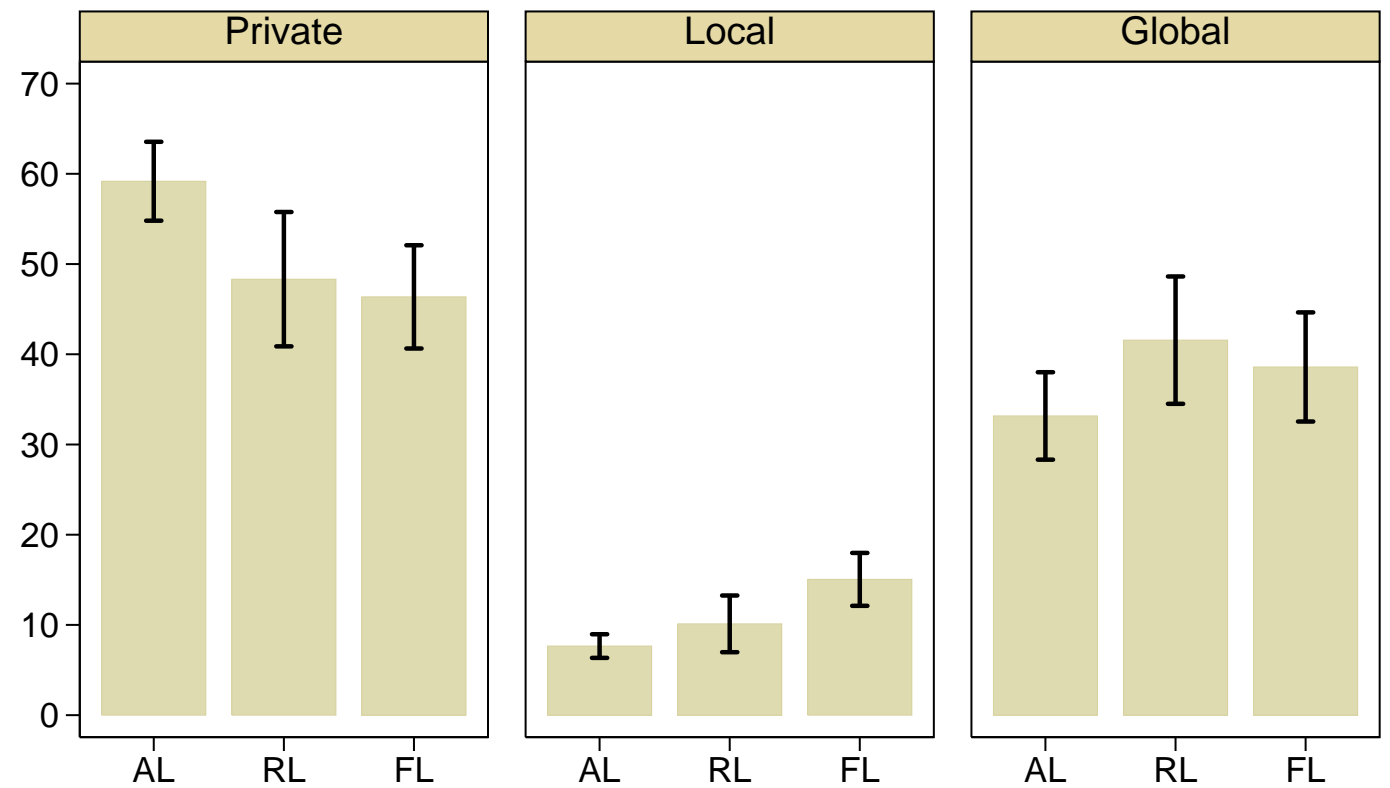

B. Effect of Group Matching with High Gains to Cooperation
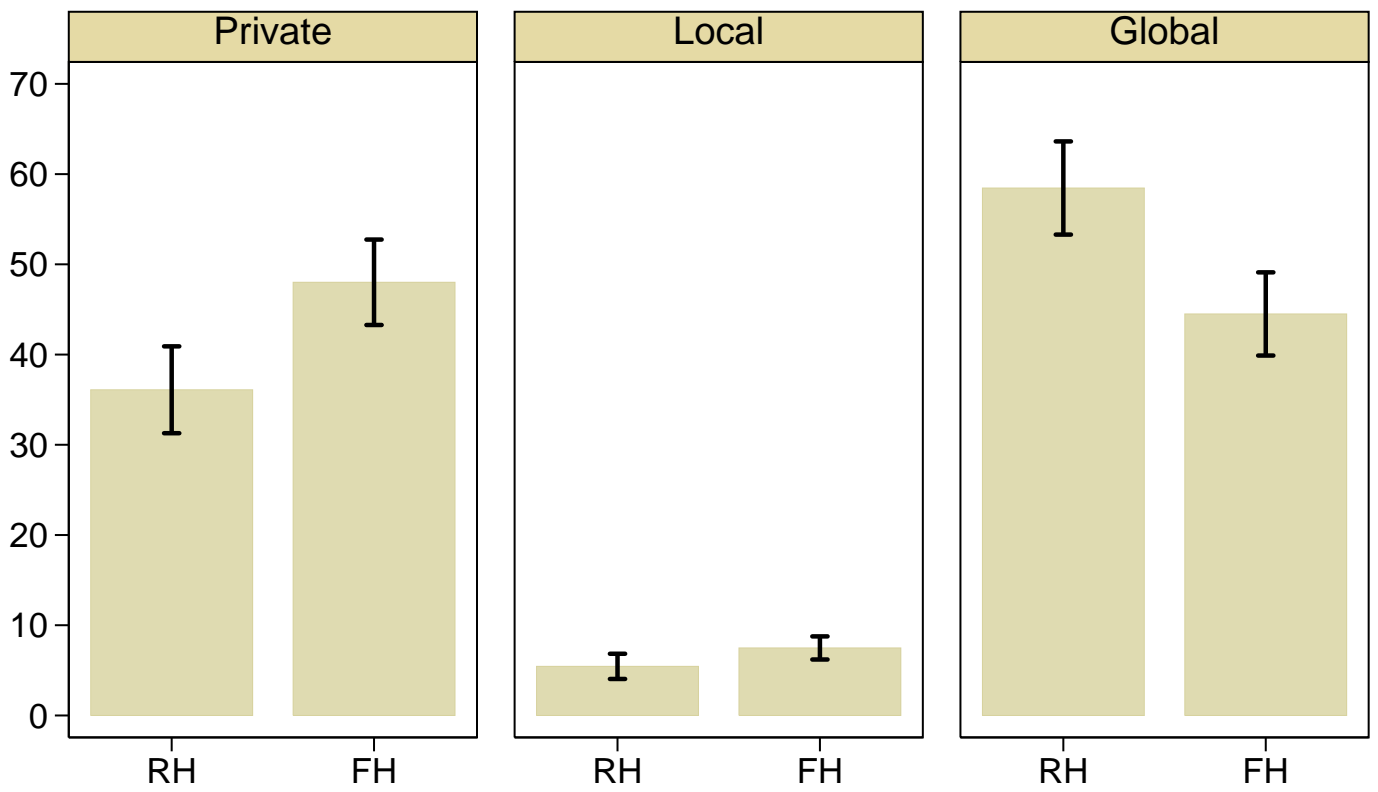

Note: confidence bars are +/- 1 SEM, treating group pairs as observations. 
Both the graphical presentation in Figure 3 as well as the summary statistics in Table 1 confirm that our results are directionally consistent with these predictions: contributions to the local account are highest under FL (15.0\%) followed by RL (10.1\%) and AL (7.7\%). This comes at the expense of allocations to the private account, which are higher under AL $(59.2 \%)$ than RL $(48.3 \%)$ and FL (46.4\%). Tables 2 and 3 indicate that the difference in contributions to the local account between FL and AL is statistically significant at the $5 \%$ level both in a nonparametric test at the level of group pairs, as well as in the individuallevel regression. ${ }^{9}$ On the other hand, none of the differences between treatments RL and AL are significant in any of the analyses.

In interpreting these results, we acknowledge that the comparison between treatments FL and AL is not as clean as the one between RL and AL. Since subjects in FL also previously competed with the same out-group in the Tullock contest, the differences that we observe may also reflect an effect of negative sentiment toward the out-group as implied by Hypothesis 2. We summarize our discussion of Hypothesis 1 as follows:

Result 1: Contributions to the local public good are significantly higher under treatment FL compared to AL. Subjects are more cooperative toward the members of their in-group when they have previously jointly competed against the same out-group, compared to when they have not previously interacted with the members of either group. This result likely reflects a combination of in- and out-group effects.

Hypothesis 2 states that subjects' other-regarding preferences toward the members of their out-group may be weakened when they have previously competed against the same out-group in the Tullock contest. As a result, we expect contributions to the global public good to be lower under treatment FL compared to RL, as well as in FH compared to RH.

Once again, both Figure 3 and Table 1 confirm that our results are directionally consistent with these predictions: contributions to the global account are lower both under FL (38.6\%) compared to RL (41.6\%), as well as under FH (44.5\%) compared to RH (58.5\%). Tables 2 and 3 indicate that when gains from cooperation are high, the difference in contributions to the global account between $\mathrm{FH}$ and $\mathrm{RH}$ is significant at the $5 \%$ level in the individual-level regression, and at the $10 \%$ level in the rank-sum test at the level of group pairs. ${ }^{10}$ On the other hand, when gains from cooperation are low, none of the differences between treatments FL and RL are significant in any of the analyses.

\footnotetext{
${ }^{9}$ The offsetting difference in allocations to the private account is also significant at the $5 \%$ level in the rank-sum test in Table 2, although it is only marginally significant at the $10 \%$ level in the regression model of Table 3 .

${ }^{10} \mathrm{In}$ addition, allocations to the private account are higher in $\mathrm{FH}$ compared to $\mathrm{RH}$, and this difference is marginally significant at the $10 \%$ level in the individual-level regression model.
} 
As a result of their reluctance to cooperate with the members of an out-group with whom they have previously competed in the Tullock contest, subjects in our fixed groups treatments attain lower earnings and hence a lower level of efficiency. When the gains from cooperation are low, these costs are small and not statistically significant: average earnings drop fractionally from 146.6 under RL (out of a maximum of 200 in the low gains treatments, implying an efficiency of $73.3 \%$ ) to 146.1 under FL. This difference is clearly not significant, with $p=0.880$ in a Wilcoxon rank-sum test.

However, when the gains from cooperation are large, the costs are more substantial: average earnings drop from 219.6 under RH (out of a maximum of 300 in high gains treatments, implying an efficiency of $73.2 \%)$ to $192.7(64.2 \%)$. It turns out that the efficiency of the FH treatment is the lowest out of our five treatments. In an OLS regression, analogous to the Tobit models in Table 3, in which we regress each subject's mean earnings over the ten rounds of the MLPG game on dummies for each of the treatments, with standard errors clustered at the level of group pairs, we find the difference in earnings between $\mathrm{FH}$ and $\mathrm{RH}$ to be significant with $p=0.047 .{ }^{11}$ We also find this difference to be marginally significant in a Wilcoxon rank-sum test, with $p=0.070$.

Result 2: When the gains to cooperation between groups are large, contributions to the global public good are significantly lower under treatment FH compared to RH. Subjects are less cooperative toward the members of their out-group when they have previously competed against that group, compared to when their previous interaction was with a different out-group. As a result of this out-group bias, subjects attain significantly lower levels of earnings and efficiency.

One potential concern with our interpretation of these group matching effects is that experience of the Tullock contest could be informative to subjects regarding the preferences of both in- and out-group members, and this could influence behavior in the MLPG game independently of the hypothesized effects upon their preferences. In particular, subjects in the fixed matching treatments might form more accurate beliefs as a result of having previously interacted with both their in- and out-groups. In this event, we might expect differences between treatments to decrease over the ten rounds of the MLPG game, as subjects in the rematched groups treatments learn the preferences of their new out-group. However, as can be seen from Appendix Figure A2, this is not what we observe: the differences between treatments in contributions to the local and global public goods remain stable over time, with all treatments displaying very similar time trends.

\footnotetext{
${ }^{11}$ Full results are available upon request.
} 


\subsection{Effects of gains from cooperation}

Our final hypothesis is concerned with the effects of our low versus high gains from cooperation manipulation, and corresponds to the vertical dimension in Figure 2. We summarize these effects graphically in Figure 4, separately for each of the three accounts, and for treatments with rematched and fixed groups. Once again, the confidence bars in this figure represent \pm 1 standard error of the mean, treating group pairs as observations.

Hypothesis 3 states that an increase in the return on contributions to the global public good, representing the magnitude of potential gains from cooperation with the outgroup, will increase the attractiveness of contributing to the global account. However, the response to this increase depends also on the strength of subjects' other-regarding preferences toward their out-group, which are also hypothesized to be weakened when the two groups have previously competed in the Tullock contest. Accordingly, we expect contributions to the global public good to be higher under treatment RH compared to RL. We also expect global contributions to be higher under FH compared to FL, however we expect this latter effect to be smaller in comparison to the rematched groups treatments.

Both Figure 4 and Table 1 confirm that our results are directionally consistent with these predictions: contributions to the global account are higher both under RH (58.5\%) compared to RL (41.6\%), as well as under FH (44.5\%) compared to FL (38.6\%). Moreover, the difference under rematched groups $(16.9 \%)$ is almost three times larger than under fixed groups (5.9\%). As a result, Tables 2 and 3 indicate that under rematched groups, the difference in contributions to the global account between RH and RL is statistically significant at the $5 \%$ level both in a nonparametric test at the level of group pairs, as well as in the individual-level regression.

On the other hand, under fixed groups the difference in global contributions between FH and FL is not significant in either of the analyses. Thus when there is a prior history of conflict between the two groups, subjects appear to be largely unmoved by an increase in the return to cooperating with the out-group.

Result 3: Contributions to the global public good are significantly higher under treatment RH compared to RL. Subjects respond to an increase in the return to cooperating with the out-group when the two groups have not previously interacted. However, when the two groups have previously competed against one another, there is no significant response.

Finally, we note one result not predicted by our model: contributions to the local public good are higher under FL compared to FH, and this difference is clearly significant - at the $5 \%$ level in the Wilcoxon test, and at the $1 \%$ level in the regression analysis. 


\section{A. Effect of Gains from Cooperation in Rematched Groups}
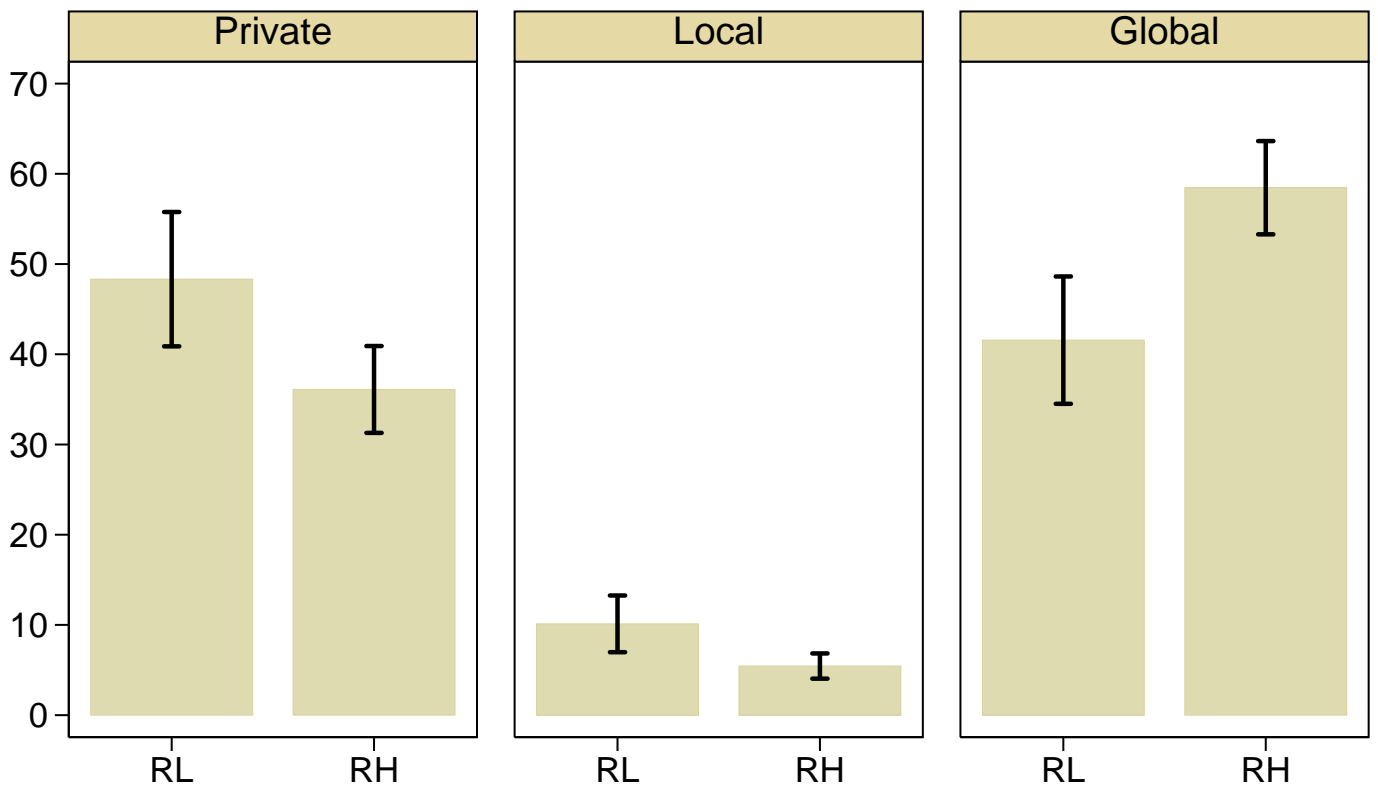

\section{B. Effect of Gains from Cooperation in Fixed Groups}
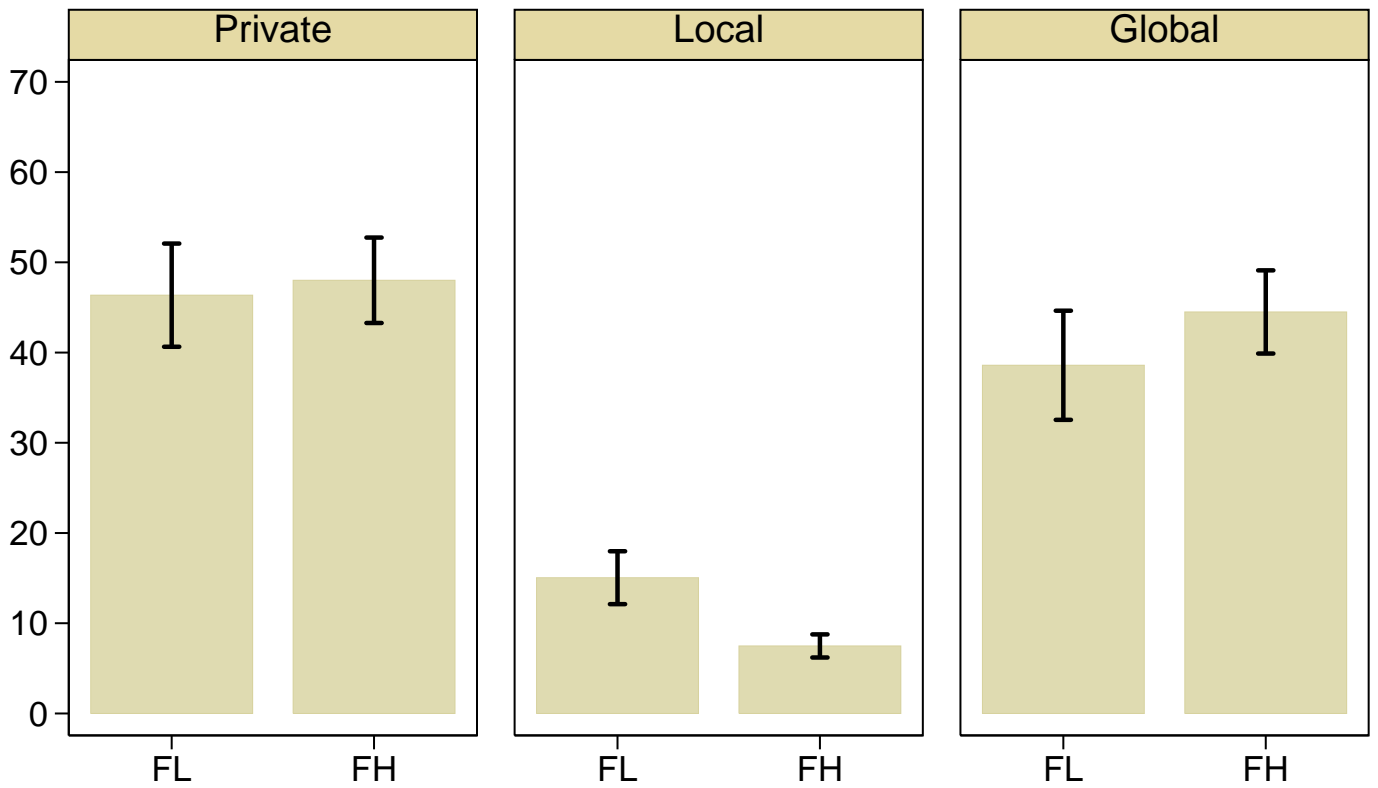

Note: confidence bars are +/- 1 SEM, treating group pairs as observations. 


\subsection{Tullock contest}

Since our group matching treatments were intended to manipulate subjects' experience of conflict, we now verify that the Tullock games were indeed keenly contested. Appendix Figure A1 plots the mean individual proposed investment in the group contest fund for each round of the Tullock game. ${ }^{12}$ In our design, the actual investment that was binding on each subject is the median of the amounts proposed by the three members of their in-group; Figure A1 also plots the mean of this group median.

Recall that each subject has an endowment of 100 in each round, and that the risk-neutral Nash investment at the individual level is 25 . Figure A1 indicates that the mean proposed investments are substantially higher, and typically around double the Nash level. Further, the group medians are on average very close to the individual means, indicating that the high mean proposals are not driven by outlying group members. There is no discernible time trend in the level of contest investments over time, and in particular there is no evidence of convergence toward the Nash investment.

To give an indication of the extent of heterogeneity in the intensity of conflict in different group pairs, we compute the mean of the six individual proposals within each group pair, and depict the inter-quartile range of these means with respect to the forty group pairs as the shaded region in Figure A1. This confirms that while there are indeed differences in the intensity of conflict between group pairs, even the comparatively less competitive group pairs nonetheless invest at substantially higher than the Nash level.

\subsection{Discussion}

Our results demonstrate that competition does indeed make group membership more salient than arbitrary group identity in a laboratory setting. Contributions to the local account are significantly higher in the FL treatment compared to AL (Result 1). Interestingly, while the effect is directionally the same when comparing RL to AL, the difference is not statistically significant. Since decisions in the FL treatment are affected by preferences toward both in- and out-group members, the difference in allocations to the local account in FL compared to AL may be driven in part by a decrease in generosity toward an out-group with whom one has previously been in conflict (i.e. a decrease in $b$ in equation 4 , as well as an increase in $a$ ).

Another intriguing possibility is that different preferences for cooperation with the ingroup may be activated when continuing to interact with the same out-group as in the

\footnotetext{
${ }^{12}$ This figure omits the data of the AL treatment, in which subjects played the Tullock contest as the second stage, following the MLPG game.
} 
contest. In terms of our model, the increase in $a$ following conflict may be dependent on whether the in-group interacts with the same, or a different, out-group. Either of these mechanisms would suggest that inter-group competition is a useful tool for inducing salient group identity in economic experiments: the Tullock contest produced behavior that differed significantly from arbitrary group identity. This opens the possibility of using this, or other, forms of inter-group competition to examine questions relating to group identity in economic experiments.

While we observe greater cooperation within groups following conflict, there are substantial negative effects on efficiency - as a result of reduced cooperation between groups when the MLPG game is played with the same out-group as the Tullock game. In our high returns from cooperation condition, contributions to the global account are lower in treatment $\mathrm{FH}$ - where the groups previously competed against one another - compared to RH (Result 2). Moreover, in our fixed-matching condition we find no significant increase in allocations to the global account in treatment FH compared to FL. On the other hand, allocations to the global public good increase significantly in the corresponding rematched-groups treatments (Result 3), which is consistent with previous research on the MLPG game using milder forms of group identity (Blackwell and McKee, 2003; Fellner and Lünser, 2008). Taken together, these results indicate that the findings of the previous studies may not be robust to the form of the group identity manipulation.

The muted response to higher returns from cooperation in our fixed matching treatments has important implications for naturally-occurring conflict. In our experiment, conflict in the Tullock contest is socially inefficient. However in other settings, competition may help to achieve socially efficient outcomes. For example, in a laboratory experiment Nalbantian and Schotter (1997) find that among several schemes commonly used by employers to incentivize workers, creating competition among teams is the most efficient (see also Guillen et al., in press). However, if conflict also decreases the potential for teams to cooperate with each other in future, the overall effect of incentivizing intergroup competition may well be negative. As a result of their prior history of competition, changes in preferences toward (or beliefs about) members of a formerly-competing team may impede future cooperation, resulting in lower profits for the firm in the long run.

Behavior in public good games has been explained by several mechanisms, including altruism (Andreoni, 1990), aversion to inequality (Fehr and Schmidt, 1999; Bolton and Ockenfels, 2000), preferences for social efficiency (Charness and Rabin, 2002) and reciprocity (Rabin, 1993; Dufwenberg and Kirchsteiger, 2004; Falk and Fischbacher, 2006). Our model is agnostic on which of these mechanisms drives the effects that we observe, in the sense that one or more of these forces may be responsible for shifting the reduced-form utility weights, $a$ and $b$, that an individual attaches to the payoffs of others. Moreover, 
while our results are consistent with previous research showing that group identity affects both in- and out-group preferences, the form of conflict that we introduce in our design, namely competition over a fixed resource, may operate through distinct behavioral channels to other forms of salient group identity.

While more research is needed to explore this issue, our findings are also broadly consistent with field experiments such as Gumen (2012) and Buchan et al. (2009) who find ingroup biases in similar designs using naturally-occurring group identities, as well as with previous work suggesting a link between parochialism and violent conflict (Choi and Bowles, 2007; Voors et al., 2012; Bauer et al., 2014). The fact that we find a similar effect in a neutrally-framed laboratory setting suggests that the mere act of competition over a fixed-resource increases in-group bias, even in the absence of underlying ethnic divisions, cultural stereotyping, or exposure to violence.

\section{Conclusion}

In this paper, we present the results of a laboratory experiment in which we manipulate the nature of subjects' prior exposure to conflict, to study its effects upon subsequent cooperation both within and between groups. Our design introduces a novel method to induce a stronger form of group identity in the lab, which enables us to disentangle the role of conflict in strengthening in-group identity from its effect in changing preferences towards an out-group. We also examine the response to changes in the returns to intergroup cooperation when there has been a past history of conflict between the groups.

We find that group identity is indeed strengthened by exposure to the Tullock contest, and that subjects demonstrate stronger in-group preferences when there has been a shared history of conflict between the in- and out-groups. We also find that prior exposure to conflict involving a specific out-group matters independently of the common in-group experience of conflict. Moreover, we find no response to an increase in the returns to between-group cooperation when there has been a previous history of conflict involving the same out-group. This neatly demonstrates how inter-group conflict - even in the setting of a laboratory experiment - can lead to less socially efficient outcomes.

Our results are consistent with a simple model in which an individual's other-regarding preferences are sensitive to group identity, such that increases in the material payoffs of in-group members may be weighted more heavily than corresponding increases in the payoffs of the out-group. We find that a shared experience of conflict with one's in-group increases the weight attached to in-group payoffs, while a history of conflict involving a specific out-group decreases the utility of out-group payoffs. This implies that conflict 
increases parochialism both by increasing preferences for in-group cooperation, and also by decreasing preferences for out-group cooperation.

Our findings are also consistent with those of several field experiments using naturallyoccurring group identity and conflict. The fact that we observe similar effects suggests that competition itself plays a role in forming group identity, independent of more deeplyseated sources of group affiliation and conflict. 


\section{References}

Abbink, K., 2012. Laboratory experiments on conflict, in: Garfinkel, M.R., Skaperdas, S. (Eds.), The Oxford Handbook of the Economics of Peace and Conflict. Oxford University Press, New York.

Abbink, K., Brandts, J., Herrman, B., Orzen, H., 2010. Intergroup conflict and intra-group punishment in an experimental contest game. American Economic Review 100, 420-447.

Andreoni, J., 1990. Impure altruism and donations to public goods: A theory of warm-glow giving. Economic Journal 100, 464-477.

Bauer, M., Cassar, A., Chytilova, J., Henrich, J., 2014. War's enduring effects on the development of egalitarian motivations and in-group biases. Psychological Science 25, 47-57.

Blackwell, C., McKee, M., 2003. Only for my own neighborhood? Preferences and voluntary provision of local and global public goods. Journal of Economic Behavior and Organization $52,115-131$.

Bolton, G.E., Ockenfels, A., 2000. ERC: A theory of equity, reciprocity, and competition. American Economic Review 90, 166-193.

Bowles, S., Gintis, H., 2011. A Cooperative Species: Human Reciprocity and Its Evolution. Princeton University Press, Princeton.

Brunwasser, M., 2011. Bosniaks and Croats, divided in class and at play. International Herald Tribune July 2.

Buchan, N., Grimalda, G., Wilson, R., Brewer, M., Fatas, E., Foddy, M., 2009. Globalization and human cooperation. Proceedings of the National Academy of Sciences 106, 4138-4142.

Chakravarty, S., Fonseca, M., 2013. Discrimination via exclusion: An experiment on group identity and club goods. University of Exeter, Economics Department Discussion Paper 13/02.

Charness, G., Rabin, M., 2002. Understanding social preferences with simple tests. Quarterly Journal of Economics 117, 817-869.

Charness, G., Rigotti, L., Rustichini, A., 2007. Individual behavior and group membership. American Economic Review 97, 1340-1352.

Chen, Y., Li, S.X., 2009. Group identity and social preferences. American Economic Review 99, 431-457.

Choi, J., Bowles, S., 2007. The coevolution of parochial altruism and war. Science 318, 636-640.

Dufwenberg, M., Kirchsteiger, G., 2004. A theory of sequential reciprocity. Games and Economic Behavior 47, 268-298.

Eckel, C., Grossman, P., 2005. Managing diversity by creating team identity. Journal of Economic Behavior and Organization 58, 371-392.

Falk, A., Fischbacher, U., 2006. A theory of reciprocity. Games and Economic Behavior 54, 293-315.

Fehr, E., Schmidt, K.M., 1999. A theory of fairness, competition, and cooperation. Quarterly Journal of Economics 114, 817-868. 
Fellner, G., Lünser, G., 2008. Cooperation in local and global groups. WU Vienna University of Economics and Business, Department of Economics Working Paper 122.

Fischbacher, U., 2007. z-Tree: Zurich toolbox for ready-made economic experiments. Experimental Economics 10, 171-178.

Gneezy, A., Fessler, D., 2012. Conflict, sticks and carrots: War increases prosocial punishments and rewards. Proceedings of the Royal Society B: Biological Sciences 279, 219-223.

Greiner, B., 2004. An online recruitment system for economic experiments, in: Kremer, K., Macho, V. (Eds.), Forschung und wissenschaftliches Rechnen 2003. Gesellschaft für Wissenschaftliche Datenverarbeitung, Göttingen, pp. 79-93.

Guillen, P., Merrett, D., Slonim, R., in press. A new solution for the moral hazard problem in team production. Management Science .

Gumen, A., 2012. Ethnic conflict and the provision of public goods: A framed field experiment. Mimeo .

Halevy, N., Weisel, O., Bornstein, G., 2012. In-group love and out-group hate in repeated interactions between groups. Journal of Behavioural Decision Making 25, 188-195.

Hirshleifer, J., 1995. Theorizing about conflict, in: Hartley, K., Sandler, T. (Eds.), Handbook of Defense Economics. North Holland, pp. 166-189.

Ke, C., Konrad, K.A., Morath, F., 2013. Brothers in arms - An experiment on the alliance puzzle. Games and Economic Behavior 77, 61-76.

Nalbantian, H.R., Schotter, A., 1997. Productivity under group incentives: An experimental study. American Economic Review 87, 314-341.

Puurtinen, M., Mappes, T., 2009. Between-group competition and human cooperation. Proceedings of the Royal Society B: Biological Sciences 276, 355-360.

Rabin, M., 1993. Incorporating fairness into game theory and economics. American Economic Review 83, 1281-1302.

Sheremeta, R.M., 2013. Overbidding and heterogeneous behavior in contest experiments. Journal of Economic Surveys 27, 491-514.

Tajfel, H., 1971. Social categorization and intergroup behavior. European Journal of Social Psychology 1, 148-179.

Tajfel, H., Turner, J.C., 1979. An integrative theory of intergroup conflict, in: Austin, W., Worchel, S. (Eds.), The social psychology of intergroup relations. Brooks/Cole, Monterey, CA, pp. 33-47.

Tullock, G., 1980. Efficient rent-seeking, in: Buchanan, J., Tollison, R., Tullock, G. (Eds.), Towards a Theory of the Rent-Seeking Society. Texas A\&M University Press, pp. 97-112.

Voors, M., Nillesen, E., Verwimp, P., Bulte, E., Lensink, R., Soest, D.V., 2012. Violent conflict and behavior: A field experiment in Burundi. American Economic Review 102, 941-64. 


\section{Appendix A. Additional analyses}

Figure A1: Time path of Tullock contest investments (excluding treatment AL)

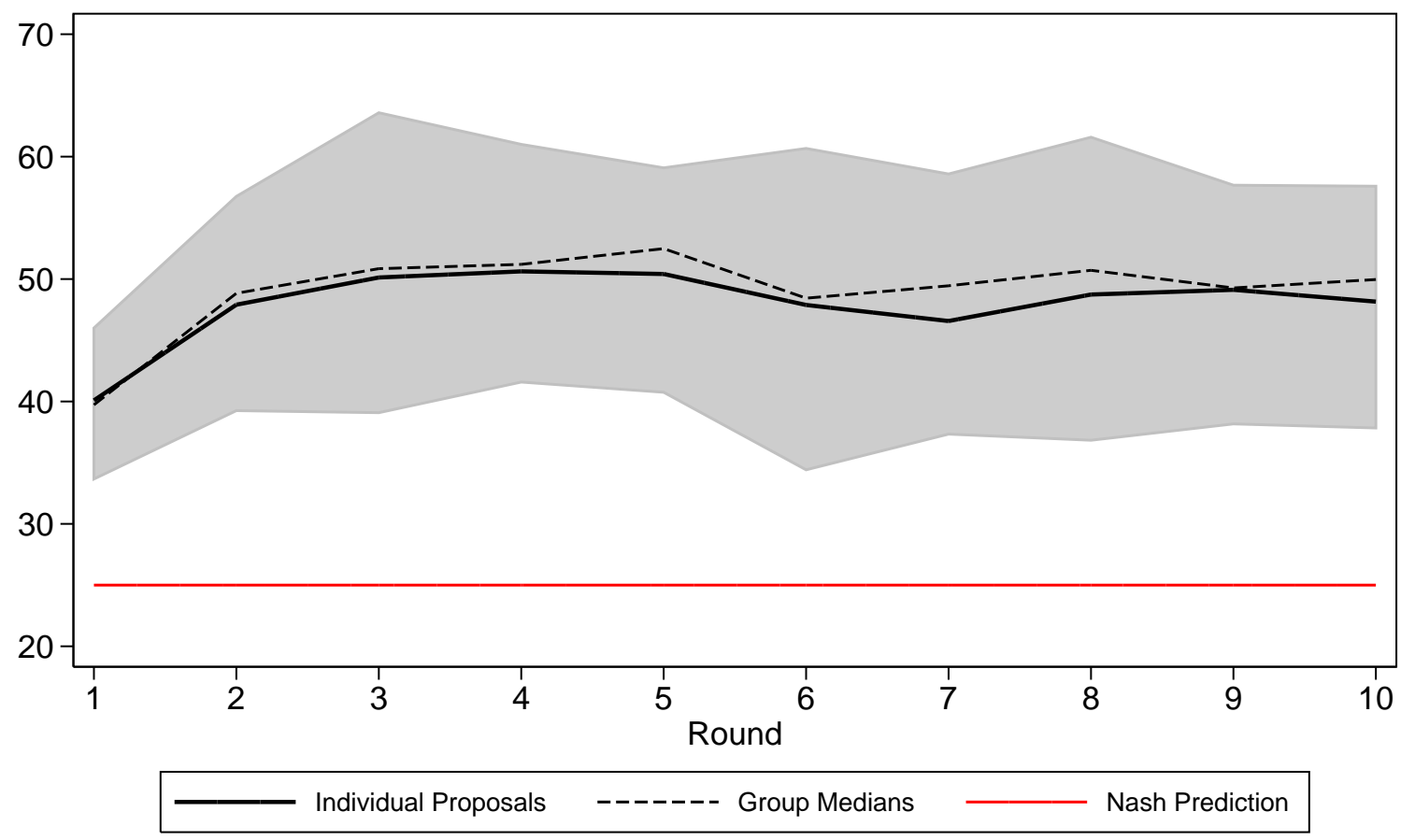

Note: shaded region is the interquartile range of the mean individual proposal, by group pairs.

Figure A2: Time paths of MLPG contributions, by account and treatment
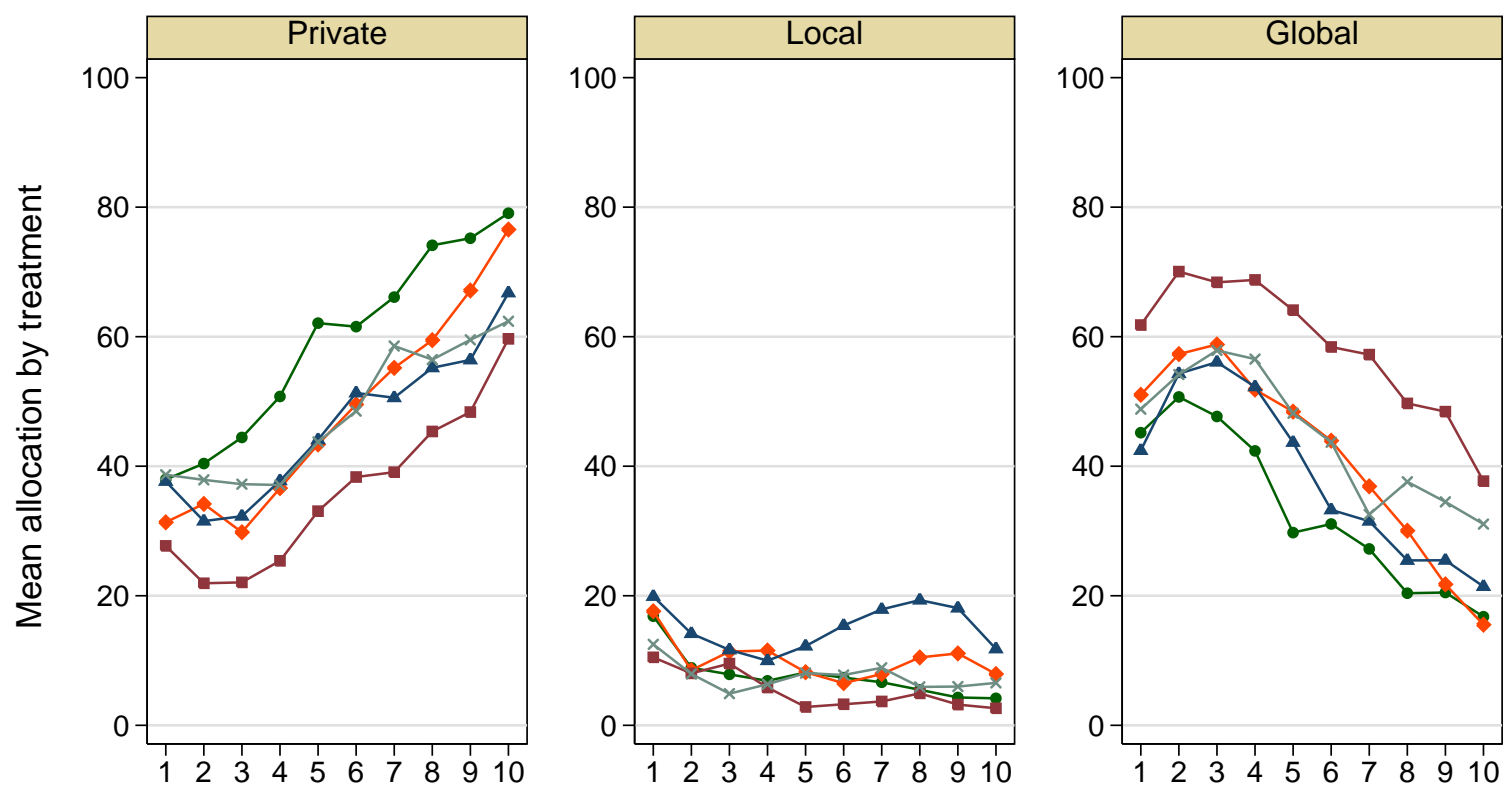

Round

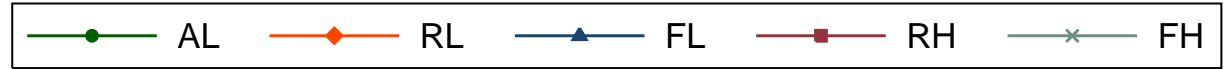




\section{Appendix B. Instructions for the RL treatment (for online publication only)}

\section{General instructions}

Welcome to this session. From now on, please do not talk to the other participants, or communicate with them in any other way. Mobile phones must also be switched off. If you have a question, please raise your hand and one of us will come to you and assist you in private. These rules are important. If you break any of these rules, we will cancel the session and dismiss all of you without any payment.

In this experiment you will make a number of decisions. These instructions explain the decisions that you will make and their consequences. Depending on your decisions you will earn money which will be paid to you in cash at the end of the experiment.

Throughout the experiment we will record all earnings in "tokens". At the end of the session, we will randomly select two decision rounds to count toward your earnings. The tokens that you earn in these two rounds will be converted into Czech crowns at the following exchange rate:

\section{1 token $=1 \mathrm{CZK}$}

\section{First task}

This task will consist of 10 rounds. At the end of the session, we will randomly draw a number between 1 and 10 from a bag to select one of these rounds, and you will be paid your earnings from this randomly chosen round.

At the beginning of this task you will be matched with two other randomly selected people in the room, to form a group of three. Your group will play against one of the other groups who will be your opponents. The other members of your group, as well as your opponents, remain the same through all ten rounds of this task. You will not learn who your group members or opponents are, either during or after today's session. Likewise, neither your group members nor opponents will learn of your identity.

In each round your group and your opponents will compete for a prize as we will now explain. At the beginning of each round, you will be given an endowment of 100 tokens. Each group must decide how many tokens to allocate to its "contest fund". This decision is made in the following way. Each group member will be asked to propose a number of tokens to allocate to the contest fund. The computer will then determine the median amount proposed by the three members. (The median is the middle number of an increasing series of numbers: the median of 1,2 and 3 is 2 ; the median of 1,98 and 100 is 98 .) This amount will be automatically deducted from each member's endowment and allocated to the group's contest fund. Any tokens not allocated to the contest fund will be yours to keep. Since each group member must allocate the same amount to the contest fund, each member will end up with the same balance of tokens. Likewise, your opponents will decide how many tokens to allocate to their contest fund in exactly the same way.

After each group has chosen its allocation to the contest fund, the computer will conduct a random draw to determine whether your group or your opponents win the prize. The prize is 
worth 300 tokens, which is divided equally among the members of the group that wins it (100 for each member). Your group's chances of winning depend on how many tokens are in its contest fund. This works as follows: imagine that each token allocated to the contest fund by your group and by the other group are placed in a bag, and then one token is randomly drawn from this bag. If the token that is drawn belongs to your group, then your group wins the prize. If the token belongs to the other group, then the other group wins the prize. Each group's chances of winning depend on the number of tokens that it has allocated relative to the number of tokens allocated by the other group.

For instance, if your group and your opponents each allocate the same amount to the contest fund, each group has the same number of tokens in the bag and an equal chance of winning (a $1 / 2$ chance). If your group allocates twice as many tokens to its contest fund as your opponents, your group has twice the chances of winning (your group has a $2 / 3$ chance of winning and the other group has a $1 / 3$ chance). Thus, your group's chances of winning increase with the amount that it allocates to the contest fund, and decrease with the amount allocated by your opponents. If your group allocates nothing and the other group allocates 1 or more tokens, than the other group automatically wins. If neither group allocates anything to the contest fund, then both groups have a $1 / 2$ chance of winning.

After the computer has determined the winner, you will be informed which group won the prize and shown your earnings for that round. Your earnings are equal to your initial endowment of 100 tokens, minus the number of tokens you allocated to the contest fund, plus 100 tokens if your group won the prize. Since each group member must allocate the same number of tokens to the contest fund in each round, each group member's earnings will also be the same in each round.

\section{Second task}

This task will again consist of 10 rounds. At the end of the session, we will randomly draw a number between 1 and 10 from a bag to select one of these rounds, and you will be paid your earnings from this randomly chosen round.

For this task, you will again be a member of the same group of three people with whom you were matched in the previous task. This group will now be paired with a second group of three, who were also matched with one another in the previous task, and who we will refer to as the "other group". As before, you will never know the identities of any of these people, and they will never know your identity.

\section{The other group will not be the same as the group that was your opponent in the first task.}

At the beginning of each round, you will be given an endowment of 100 tokens. You will be asked to decide how many of these tokens you will allocate to three accounts: Account A, Account B and Account C. Your total earnings will depend on the amount that you and others allocate to each of the accounts as explained below: 


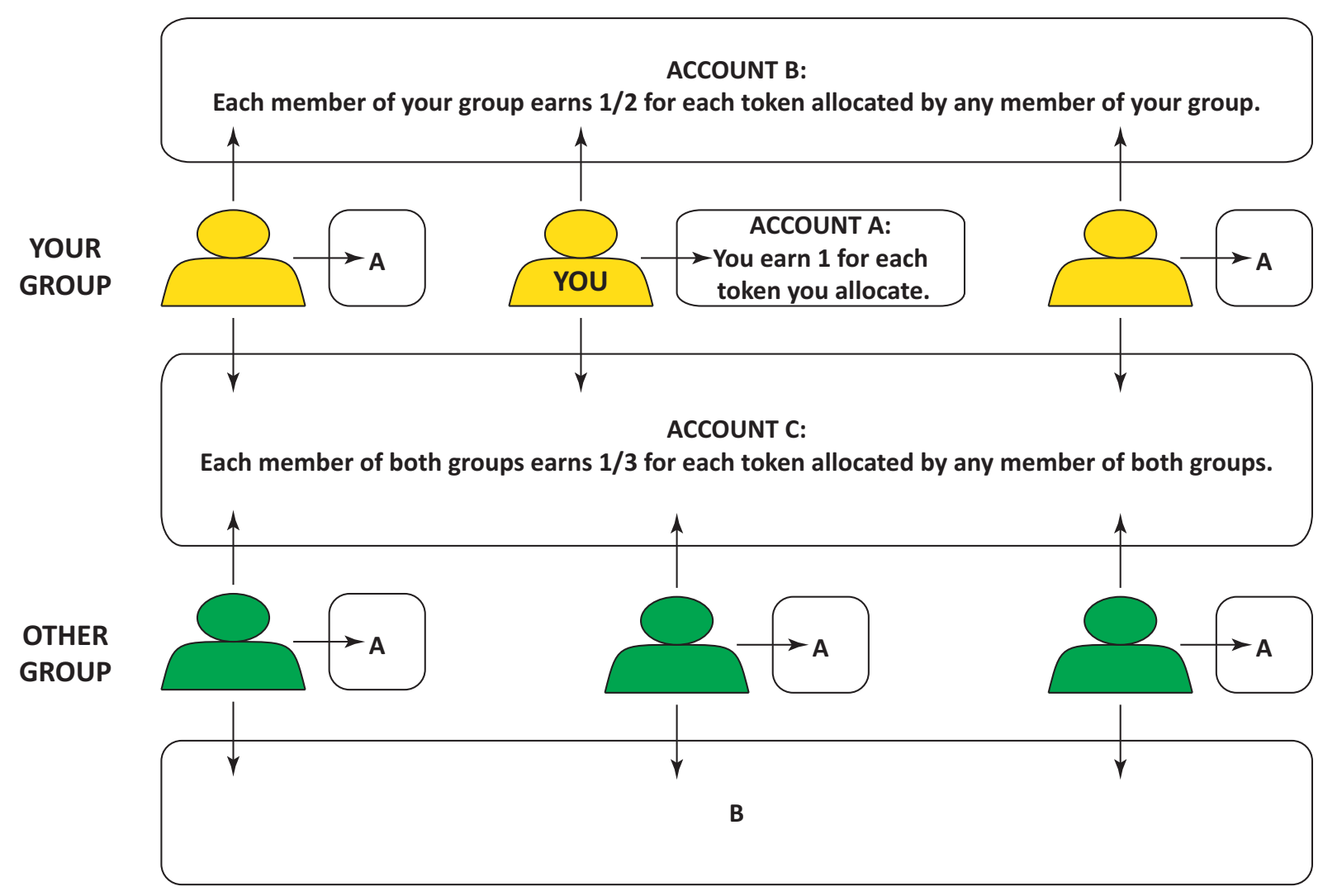

\section{Your earnings from Account A}

Each token that you allocate to Account A will earn one token for you alone. Therefore if you allocate X tokens to Account A, you will earn exactly X tokens from Account A.

No-one other than you earns anything from the tokens you allocate to Account A. Likewise, you will not earn anything from any tokens allocated to Account A by any other person.

\section{Your earnings from Account $B$}

Tokens allocated to Account B only affect the earnings of the three members of your own group. For every token allocated to Account B, by any member of your group, each member of your group will earn $1 / 2$ tokens, regardless of whether he or she allocated any tokens to Account B.

Your earnings from Account $\mathrm{B}=1 / 2 \mathrm{x}$ (sum of three allocations to Account $\mathrm{B}$ )

The earnings from Account B are calculated in the same way for all three members of your group, so all members of your group each receive the same earnings from Account B as you do. Therefore, all members of your group each benefit equally from every token that any member allocates to Account B.

For each token that you allocate to Account A, you earn one token. Suppose that you allocate this to Account B instead. Then the total amount allocated to Account B increases by one token, and your earnings from Account $\mathrm{B}$ increase by $1 / 2$ tokens.

At the same time, the earnings of the other members of your group also increase by $1 / 2$ tokens each, so the total earnings from Account B for all three group members would increase by $3 / 2$ tokens in total. 
Your allocation to Account B therefore increases the earnings of the other two members of your group, and similarly their allocations to Account B also increase your earnings. For each token that another member of your group allocates to Account B, you also earn $1 / 2$ tokens.

So, if all 3 members of your group allocate 1 token to Account B, then Account B contains 3 tokens in total, and each group member will receive $3 / 2$ tokens. In total, your group would earn $3 \times 3 / 2=9 / 2$ tokens from Account B.

Tokens allocated to Account B only affect the earnings of the members of your own group. They do not affect the earnings of the other group of three with whom your group is matched.

The members of the other group can allocate tokens to their own Account B, and this will not affect the earnings of you or the other members of your own group.

\section{Your earnings from Account $C$}

Tokens allocated to Account $\mathrm{C}$ affect the earnings of both the three members of your own group, as well as the three members of the other group. For every token allocated to Account $\mathrm{C}$, by any member of either group, each member of both groups will earn $1 / 3$ tokens, regardless of whether he or she allocated any tokens to Account C.

Your earnings from Account $\mathrm{C}=1 / 3 \mathrm{x}$ (sum of six allocations to Account $\mathrm{C}$ )

The earnings from Account $\mathrm{C}$ are calculated in the same way for all six members of both groups, so all members of both groups each receive the same earnings from Account $\mathrm{C}$ as you do. Therefore, all members of both groups each benefit equally from every token that any member of either group allocates to Account C.

For each token that you allocate to Account A, you earn one token. Suppose that you allocate this to Account $\mathrm{C}$ instead. Then the total amount allocated to Account $\mathrm{C}$ increases by one token, and your earnings from Account $\mathrm{C}$ increase by $1 / 3$ tokens.

At the same time, the earnings of the other members of both groups also increase by $1 / 3$ tokens each, so the total earnings from Account $\mathrm{C}$ for all six members of both groups would increase by 2 tokens in total.

Your allocation to Account $\mathrm{C}$ therefore increases the earnings of the other five members of both groups, and similarly their allocations to Account $\mathrm{C}$ also increase your earnings. For each token that another member of either group allocates to Account C, you also earn $1 / 3$ tokens.

So, if all 6 members of both groups allocate 1 token to Account $\mathrm{C}$, then Account $\mathrm{C}$ contains 6 tokens in total, and each member of both groups will receive 2 tokens. In total, both groups would earn $6 \times 2=12$ tokens from Account C.

Your total earnings from this task

Your earnings $=$ Your own allocation to Account A

$+1 / 2 \times$ (sum of three allocations to Account B)

$+1 / 3 \times$ (sum of six allocations to Account C) 